\title{
Agroforestry as a catalyst for on-farm conservation and diversification
}

\author{
Diomy Zamora $\cdot$ Ranjith P. Udawatta
}

Received: 14 August 2016/Accepted: 8 September 2016/Published online: 17 September 2016

(C) Springer Science+Business Media Dordrecht 2016

\begin{abstract}
The vision of the first Agroforestry Conference held in Guelph, Canada was "to provide a forum within which people working in temperate North America agroforestry systems could interact and exchange idea". Agroforestry research has progressed considerably over the last 25 years. The wealth of information generated over the years has helped understand the role that agroforestry can play to achieve production, environmental, economical, and social benefits of adoption of the practice. The aim is to further strengthen our understanding of how temperate agroforestry can be deployed in the landscape as a tool towards sustainable farm management practice. Seventeen manuscripts in this special issue from oral and poster presentations of the $14^{\text {th }}$ North American Agroforestry Conference addressed a wide range of agroforestry topics from promoting agroforestry adoption, production, and marketing; to understanding agroforestry's role in impacting soil,
\end{abstract}

D. Zamora $(\bowtie)$

University of Minnesota Extension and Department of

Forest Resources, College of Food Agriculture and

Natural Resource Sciences, 1530 Cleveland Ave N,

St. Paul, MN 55108, USA

e-mail: zamor015@umn.edu

\section{R. P. Udawatta}

Department of Soil, Environmental and Atmospheric

Sciences, Center for Agroforestry, School of Natural

Resources, 203 ABNR, University of Missouri, Columbia,

MO 65211, USA

e-mail: UdawattaR@missouri.edu water quality, climate change mitigation, and species diversity.

Keywords Land management $\cdot$ NAAC $\cdot$ Research challenges - Temperate agroforestry

\section{Introduction}

Agroforestry is an intensive land management practice where trees are deliberately integrated with crops, pastures, and/or with animals for environmental and economic benefits (Gold and Garrett 2009). Although the practice began thousands of years ago and has continued in various parts of the world for food, fiber, shelter and other benefits; systematic scientific studies evolved only recently. Within the last 25 years, a number of international journals have published agroforestry related research articles, containing biophysical research and the contribution of agroforestry for on-farm conservation and diversification. Dissemination of knowledge and adoption of scientifically proven management options are becoming popular in every geographic region. In spite of an increasing knowledge base, research in some areas, including long-term biophysical studies and markets, is still lacking. For land managers and policy makers, filling these knowledge gaps is critical in the development of sustainable agricultural practices and policies.

Agroforestry provides a broad range of ecosystem services and environmental benefits (Jose 2009), 
however, these can vary by ecological and economic region. To develop quality models that generalize and broaden our understanding of agroforestry, it is imperative that scientists gather information that is region specific. Soil, climate, trees, crops, and animals are location specific and practices developed in one region may not be ideally suited to the soil fauna and flora of a different region. Furthermore, in temperate climates with more mechanized agriculture, agroforestry should be established with careful consideration of landscape, capital investments, income, and environmental benefits. The application of research, models, and demonstrations at a regional scale is necessary for an improved environment and an improved standard of living for those who depend on the land to earn their livelihood.

This special Volume of Agroforestry Systems includes 17 manuscripts presented at the 15th North American Agroforestry Conference held in Ames, Iowa, from May 31 to June 3, 2015. Researchers, landowners, and policy makers from various regions of the temperate zone attended that meeting which proved that there was a need for continued agroforestry research, from establishment guidelines to economics and long-term environmental benefits. This volume is proof of how far temperate agroforestry has come over the last 25 years and its research advancements in environmental benefits, socio-economics, and policy making support systems for multi-dimensional, multi-disciplinary agroforestry practices.

\section{Main contributions for this special issue}

The 17 manuscripts in this special issue cover a wide range of agroforestry topics from promoting agroforestry adoption, production, and marketing; to understanding agroforestry's role in impacting soil, water quality, climate change mitigation, and species diversity. Although the common theme in each of these manuscripts is agroforestry, each paper is unique in its subject and approach. Two manuscripts discuss approaches and challenges of promoting agroforestry at the landowner and agency levels. Screening and selection of genotypic traits of shrubs suitable for agroforestry application, and the effects of stocking rates on livestock is the foci of three manuscripts. Topics of two papers are on changes in soil physical and chemical properties as influenced by agroforestry.
Water quality, and role of agroforestry on snow control are the subject of two papers, which elaborate on surface and subsurface water quality and agroforestry effects. Modeling to understand role of agroforestry on climate change impacts, economics of living snow fence agroforestry, role of agroforestry on climate change mitigation, and biomass production of agroforestry systems are the focus of four six manuscripts. The other two papers describe bird species diversity, and optimizing resource allocation in agroforestry systems. This volume portrays agroforestry as a multidisciplinary science contributing to worldwide interest in sustainable production systems.

This volume leads off with a discussion of factors that are important when promoting agroforestry for environmental benefits and economics. According to Karki et al. providing technical support to landowners and equipping natural resource professionals on agroforestry are crucial to agroforestry adoption. Similarly, Mayerfeld et al. found that natural resource professionals and landowners need deeper understanding of the establishment, economics and best management practices of silvopasture to increase adoption of the practice in the Upper Midwest, USA. Their study demonstrated the crucial role of outreach and extension activities as well as the role that natural resource professionals have to increase agroforestry adoption.

In addition to understanding indirect social and direct financial incentives for adoption of agroforestry, much research has been done on the adoption of agroforestry in order to improve the productive use of existing land. Research on production economics of living snow fences in the Upper Midwest was the focus of Smith et al. while goat silvopasture to control understory vegetation in Longleaf Pine Stands was the focus of Gurung et al. The study conducted by Gurung et al. identified economically feasible silvopasture prescriptions using goats including weed control in longleaf pine stands. The study of Smith et al. found that biomass harvesting is prohibitively expensive for a typical willow living snow fence due to the small scale production, however establishing longer corridor of willow living snow fence can defray planting, establishment and transportation cost, making willow living snow fence a viable option for producing biomass for energy.

A study by Haile et al. quantified the potential of loblolly pine-switchgrass alley cropping for provision 
of biofuel feedstock with the monoculture production of individual species. Although the production of these individual species in monoculture setting was higher, the land equivalent ratio (LER) showed that these species require $74 \%$ more land to produce the same amount of yield relative to agroforestry system. Similarly, two related experiments by Thevathasan et al. and Oelbermann et al. assessed biomass production of commonly used species in agroforestry. In Thevasthasan et al. study, different management regimes were employed including application of different fertilizer rates to assess biomass yield of five potential energy crops such as miscanthus, switchgrass, poplar, willow and mix of native polyculture grasses. The study of Oelbermann et al. on the other hand, involved the understanding of the effects of nitrogen fertilizer application on greenhouse gas emissions in two willow clones in southern Ontario, Canada, in response to understanding the climate change mitigation impacts of producing bioenergy crops.

Ogdahl et al. designed a study to understand the snow storage and biomass production potential of living willow snow fences in Minnesota. The experiment involved investigating establishment and potential snow storage capacity of three shrub-willow varieties in living snow fence planting arrangements of two and four rows. Their experiment showed that willow living snow fence could exceed local snow transport after 2-3 growing seasons post coppice. Additionally, the four-row arrangements trapped approximately $20 \%$ more snow than two-row arrangements, and willow variety did not affect snow storage.

Agroforestry systems provide environmental benefits such as improved soil health. In this special issue, research by Rajper et al. explained the effects of probiotics on soil microbial activity, biomass and enzymatic activity under cover crops in field and greenhouse setting. In their study, soil were amended with probiotics (Bio-Ag) including a non-treated control, and dosages at 60,90 , and $120 \mathrm{~L}$ probiotic $\mathrm{ha}^{-1}$ year $^{-1}$ with three replications. Results showed a positive response. Principal component analysis (PCA) revealed that $\mathrm{PC} 1$ and $\mathrm{PC} 2$ accounted for $62 \%$ of total variance. Increasing trends in the values of soil fungal communities, rhizobia, dehydrogenase (DHA), $\beta$-glucosaminidase and fluorescein diacetate hydrolase (FDA) with the $120 \mathrm{~L}$ probiotic ha ${ }^{-1}$ year $^{-1}$ dose implies that probiotics can be used to improve soil quality (SQ) indicators.

Manuscripts by Sahin et al. and Weerasekara et al. explained beneficial effects of agroforestry buffers on soil physical and chemical properties. Sahin et al. examined the effects of agroforestry and grass-legume buffers on in situ water infiltration relative to row crop management under claypan soil in northeastern, MO. The work of Weerasekera et al. on the other hand, quantified soil quality differences among agroforestry buffers, grass waterway, grass buffers, and row crop areas at distances from the tree bases in a corn (Zea mays L.)-soybean (Glycine max L.) production watershed. Results imply that permanent vegetation has improved the soil quality by enhancing soil microbial activity and organic matter accumulation, thereby contribute positively to watershed restoration. Furthermore, a manuscript by Ghezeheil et al. examined the potential of tree arrangements to optimize radiation and soil water distribution and crop yield of hedgerow intercropping systems involving Jatropha curcas and Pennisetum clandestinum using diverse tree arrangements. The authors concluded that radiation and water distribution and intercrop growth can be optimized by manipulating tree arrangement without changing tree density.

Two separate manuscripts by Ziegler et al. and Ballesteros et al. explored the use of models to understand the carbon sequestration potentials of agroforestry, focusing on windbreaks, in the US. Ziegler et al. paper demonstrated the potential of the COMET-FarmTM model as an agricultural greenhouse accounting tool. Similarly, Ballesteros et al. evaluated 15 allometric models using destructive sample of Pinus ponderosa from field windbreaks in Nebraska and Montana to understand carbon sequestration and storage potential of windbreak system in the region. These modeling exercises may enhance our capacity to predict the $\mathrm{C}$ sequestration potential of windbreaks associated with whole farm/operations in the US.

As a sustainable practice, agroforestry also provides other ecosystem services including biodiversity enhancement. Coleman et al. assessed the contributions of temperate Tree-Based Intercropping (TBI) system on avian biodiversity over time. Avian biodiversity in TBI was compared with a nearby agroecosystems including abandoned field, a conventional monocrop field, a willow plantation and a mature 
woodlot. Authors concluded that avian species richness and diversity at TBI sites was higher than other practices, which suggests that TBI systems may help maintain and even enhance avian diversity in North America.

For a greater adoption of agroforestry by landowners and farmers, there is a need to develop a sitespecific species that performs well under those conditions. Two manuscripts in this issue assessed cultivars of American hazelnut (Corylus americana) collected from the wild (Demchik et al.). Using microsatellite techniques for 10 loci, the authors compared genetic differences between the types of plants collected in the wild populations. Microsatellite DNA techniques are becoming more useful tool for selection of potential agroforestry crops from wild populations. On a similar study, Demchik et al. evaluated and compared the physical characteristics and flavors of the nutmeat of a American hazelnut selection to a high quality European hazelnut variety-Tonda di Giffoni. The study concluded that American hazelnut has a great deal of potential as an oilseed and nut crop, suitable for enterprise development for farmers wishing to adopt American hazelnut in an agroforestry setting.

\section{Challenges in temperate agroforestry research}

In spite of ongoing research and continued advances in our knowledge base, agroforestry science requires a continued emphasis on both long- and short-term research in every eco region for land users and policy makers to make informed decisions. For example, studies on the long-term benefits of agroforestry on larger watersheds are still lacking in the literature. Similarly, a greater understanding of interactions among soil, microclimate, plant, and human dimensions is lacking in the literature. Finally, barriers to agroforestry adoption, the economic value of ecosystem services, and transition costs for converting traditional farmland and timberland to agroforestry need to be examined. Future research will require multi-state and multi-agency involvement for wider application potential. Conferences, publications, as well as extension meetings along with educating younger generations on environmental benefits of agroforestry will serve to promote agroforestry and sustainable land management.

Acknowledgments We would like to thank our referees for helping in the selection and review process of manuscripts. Special thanks to the Association for Temperate Agroforestry for its support in this special issue.

\section{References}

Gold MA, Garrett HE (2009) Agroforestry nomenclature, concepts, and practices. In: Garrett HE (ed) North American agroforestry; an integrated science and practice. Agronomy Society of America, Madison, pp 45-56

Jose S (2009) Agroforestry for ecosystem services and environmental benefits: an overview. Agroforest Syst 76:1-10 